\title{
Research on Traditional Aesthetics and Educational Value of Calligraphy
}

\author{
Wei He \\ Art College of Xi'an University, 710065
}

Keywords: traditional aesthetics; Zen; calligraphy; educational value

\begin{abstract}
Zen is one of the schools of Mahayana Buddhism, and Zen aesthetics is an aesthetic ideology evolved in Zen thought, which has the greatest influence on the Chinese calligraphy. Zen aesthetics and calligraphy have a long history in China. In different historical periods, Zen aesthetics has varied impacts on calligraphy. This paper briefly explains the traditional Chinese aesthetics and especially the educational value of Zen aesthetics.
\end{abstract}

Chinese calligraphy is one of the most distinctive art forms, which has long history and rich cultural deposits. As a symbol, a culture and a mark, the calligrapher expresses his/her aesthetic feelings and elicits his/her inner world by writing the Chinese characters. Good calligraphy works are often the most realistic emotional outpouring in the calligraphers' heart, representing the unique aesthetic taste and artistic pursuit of the calligrapher. Therefore, the creation of calligraphy requires lofty ambitions and sentiments. Only in this way can the works have a higher artistic pattern and bear the abstract beauty, lyrical beauty and simple beauty.

Since its birth, the Chinese calligraphy has been based on the traditional Chinese aesthetics, complementing each other. In China's traditional aesthetic concepts, the most significant and far-reaching influence on calligraphy is the Zen aesthetic thought. Zen, one of the Buddhist schools, is a branch of Chinese Mahayana Buddhism. Zen Buddhism advocates self-realization and meditation. Zen strives for a thorough analysis of things. After the eastern spread of Buddhism, Zen thought had a great impact on the formation and promotion of Zen in China. Although Zen was spread from India to Middle Earth, Zen integrated with Confucianism and Taoism in the Central Plains after the Sui and Tang dynasties and developed into the Zen culture with Chinese cultural deposits. Zen has a unique view of things, and it emphasizes the dialectical relationship between cause and effect. Zen has influenced the Chinese artistic creation and cultural connotation since its birth. From a certain perspective, Zen aesthetics is the application of Zen's traditional Chinese humanistic spirit in the field of art.

During the Tang and Song Dynasties, Zen had the most complex and profound influence. In the late Tang and Song Dynasties, aesthetics can be summarized into four categories, namely Zen aesthetics, romantic Chu aesthetics, Taoist aesthetics and Confucian aesthetics. The academic community generally believes that the Confucian aesthetics is the starting point of traditional Chinese aesthetics, while Zen aesthetics is the maturity stage of ancient Chinese aesthetics. Zen aesthetics has a great influence on the Chinese art forms. It is easy to notice Zen aesthetics in ancient Chinese calligraphy, painting, sculpture, poetry, architecture and other art forms. The 
ethereal and elegant aesthetic concept of Zen aesthetics has greatly expanded the traditional Chinese aesthetics.

Zen aesthetics elevates the cognition of beauty to a new height. Just like Zen in Zen Buddhism, its essence is to reach a state of transcendence, to view things from a completely different perspective, and not just stay in the appearance of things. Zen aesthetics is the most profound understanding and elaboration of aesthetics.

\section{Intrinsic Value Association between Calligraphy and Zen Aesthetics}

Calligraphy and Zen have been closely related since ancient times. In history, many Chinese calligraphers used Zen as a metaphor for calligraphy and calligraphy as a metaphor for Zen. Since the late Tang Dynasty, many calligraphers had often compared calligraphy with practicing meditation, which once made no distinction between them. Many famous calligraphers regarded the creation of calligraphy works as the process of meditation practicing. In their work, they interpret the thin and ethereal pursuits as the way to pursue Zen. While emphasizing individuality, Zen aesthetics also advocates anti-traditional spirit, i.e., advocating people to constantly break away from the manacle of old authority. Some western artists didn't put forward this kind of thinking until modern times, which both respects the individual development and opposes the limitation of rules and regulations.

After years of development, China's economic society has shifted from the initial focus on quantity to the current focus on quality. With the continuous improvement of people's living standards, the appreciation standards for beauty have also changed. Many people judge beauty by simplicity. They are more willing to pursue the inner beauty of things, rather than the surface. This requirement coincides with Zen's purpose. In Zen's philosophy, unity of nature and man and harmony of all things are very important. More and more calligraphy works are now returning to Zen aesthetics, in order to achieve the tacit understanding and harmony between man and nature. According to the definition of Zen, the practitioners need to reach the state of non-object through continuous learning and comprehension, i.e., shifting from "seeing a mountain as the mountain" to "seeing a mountain as not the mountain". Zen requires practitioners to look at all things from the perspective of Zen enlightenment, and finally achieve the purpose of sudden enlightenment and pursue the original source of simplicity. Zen aesthetics first emphasizes the harmonious unity of man and nature. From a certain perspective, the pursuit of nature and the worship of truth are the essence of Zen, as well as the goal of calligraphy development.

Zen is rarely mentioned today, especially in people's daily work and life: Zen aesthetics is constantly affecting our aesthetic standard.

\section{Educational Value of Traditional Aesthetics in Calligraphy}

As the national quintessence of China, calligraphy is deeply loved by people. The traditional aesthetics in calligraphy are still full of vitality in today's society. The traditional aesthetics in calligraphy have a very wide educational value. Besides, the traditional aesthetics in calligraphy are important to promote the overall quality of students and develop the correct world outlook, outlook on life and values. The research on traditional aesthetics in calligraphy is not only the protection of the calligraphy art but also the mining and innovation of the calligraphy art. The traditional aesthetics in calligraphy mainly carry the following educational functions:

\subsection{Develop students’ cultural confidence}

Under the tide of globalization, no country can develop in a closed environment, or even be 
immune from it. The cultural exchange has become the general trend and it accords with the will of the people. However, if a country lacks cultural confidence, the cultural essence of its own nation will be easily submerged in the invasion of foreign cultures. China is one of the four ancient civilizations. The Chinese civilization has a long history. It has always stood tall and confident among the nations of the world. Chinese culture has never been a closed cultural system, and China has always stressed exchanges and integration between different cultures. Many people believe that with the five millennium's history as well as the extensive and profound culture, the Chinese culture not only has the foundation to resist the invasion of foreign culture, but also has the ability to resist the invasion of foreign culture. However, if the cultivation of cultural self-confidence is neglected, cultural advantages will be easily lost. Since modern times, China has experienced a history of humiliation. In the view of many Chinese people, once foreign culture is flooded, it would make people confused. This concern does have deep roots. After the reform and opening up, China was wide open, and all kinds of new ideas and cultures flooded in. For some time, either in academia or in education, the xenocentric phenomena had oppressed the traditional culture and traditional aesthetics with overwhelming momentum. Only in this way can China clearly realize the importance of cultural confidence for the national development, and realize that the development mode that integrates material civilization with spiritual civilization is the right choice.

It should be emphasized that the line between cultural exchange and cultural invasion is sometimes blurred. People must correctly distinguish between cultural invasion and cultural exchanges. Proper cultural exchange can not only promote the development of national cultural undertakings, but even stimulate the awakening of national culture. The Chinese people should have such cultural confidence, instead of being stuck in a rut and going against the trend. For a long time, China has basically adhered to the principle of opening to the outside world, such as Zheng He's voyages to the West, the Silk Road... We have made Chinese culture stronger by integrating the outstanding foreign cultures with the achievements of human civilization. The old saying of "absorbing the essence and discard the dregs" is a concise and comprehensive description of our correct attitude towards foreign cultures. In spite of conciseness, it has rich and profound connotation. Only by strengthening the communication with foreign cultures and absorbing the nutrients from them can China develop and prosper the Chinese culture. If a country is closed to the outside world, it cannot and dare not open its mind to economic and cultural exchanges with different countries and regions, which in itself is a sign of lack of confidence. Nevertheless, cultural confidence should not be blind. How to carry forward and develop Chinese traditional culture and how to let Chinese culture go abroad and go to the world is a problem that every Chinese should face up to.

Calligraphy, as the most representative Chinese cultural element, is extensive and profound. The traditional culture contained in calligraphy is of great significance to shaping students' cultural confidence. Through learning calligraphy, students can fully understand the value system of China's traditional culture, and get the Chinese traditional aesthetics standard. This is the key to the formation of students' self-evaluation system and to strengthen students' resistance to cultural invasion.

\subsection{Cultivate students' ability to cross-cultural communication}

Calligraphy originated in China, but calligraphy art belongs to the whole world. At present, there are many people around the world who are learning calligraphy. China's neighbors Japan and South Korea have a large number of calligraphy lovers. Nowadays, the research perspective of calligraphy can no longer be limited to the domestic circle. In recent years, the calligraphy fever has emerged in many places abroad. Whether it is official or private, there are already relatively mature normal 
mechanisms in the exchanges about calligraphy practice. Therefore, calligraphy has a significant role in promoting students' intercultural communication skills.

In this regard, Japan, China's neighbor, has done a better job and many practices are worth learning from. They often send scholars and students to exchange in the name of calligraphy exchanges, taking calligraphy as a carrier to promote the layout of various cultural undertakings and industries. Calligraphy has become a medium and a bridge. Japanese people begin to cultivate the abilities of students in their childhood, and in some points they even attach more importance to them than China do.

\subsection{Condense students' humanistic feelings}

Calligraphy contains profound humanistic factors. The learning of calligraphy requires tenacious will, which is by no means overnight. Through the learning of calligraphy, students can hone their perseverance, confidence, calmness and patience. The process of calligraphy learning is often boring, and it requires a person to calm down, to cultivate himself or herself, and to overcome the fickleness. Throughout the history, all calligraphy masters had gone through hard times and enduring patience. Young students are at a particular stage in their lives, and they often lack strength. Learning calligraphy can fundamentally condense the quality of students, clean up the dust in their hearts, and let students immerse themselves in the feelings of traditional Chinese humanities.

Through the calligraphy learning, students can learn about its history, recognize its current situation, and imagine its future. Calligraphy is the carrier of Chinese traditional culture. Students can learn about the historical background of calligraphy works and the thoughts and emotions of calligraphers through the study of calligraphy works. These works are the representative and quintessence of Chinese humanistic spirit in all ages. For example, Preface to the Poems Collected from the Orchid Pavilion, written by Wang Xizhi, contains not only the beauty of ink rhyme but also exquisite words. Regardless of literary talent or artistic conception, the works are enough to shock learners from the depths of their soul. Calligraphy learning can not only cultivate students' moral sentiment, cultivate students' aesthetic ability, but also achieve the effect of humanistic inheritance in a subtle way.

\section{Conclusions}

With the continuous development and evolution of economy and society, the life pace is increasingly accelerating, and people's desire for peace is increasing day by day under the high stress of life. The living environment of reinforced concrete has caused many discomforts in people's minds, and people are eager to return to themselves and return to the truth. Calligraphy, an art form with its unique artistic charm, has infected and influenced generations of Chinese children. The calligraphy contains a wealth of Chinese traditional aesthetics and Zen aesthetics, and it is still alive today. In the new era, the overall goal of deepening calligraphy teaching reform is how to implement calligraphy teaching well, so that calligraphy can be carried forward among young students and the educational value of calligraphy can be displayed strongly.

\section{References}

[1]Xu Haitao. Application Research of Image Thinking Training in College Students' Calligraphy Teaching [J]. China Training, 2015(20).

[2] Kang Xiaodan. Study on the Application of Image Thinking in College Calligraphy Teaching [J]. Popular Literature, 2016(15).

[3] Deng Yiyuan. Research on the Current Situation of Calligraphy Public Elective Courses in Colleges and Universities [J]. Popular Literature, 2010(1). 
[4] Liu Yinghua. How to Cultivate Aesthetic Ability in Calligraphy Teaching [J]. Jilin Education, 2012 (31).

[5] Wang Yuechuan and Gong Pengcheng. Cultural Calligraphy and Literati Calligraphy-- Eco-cultural Dialogue about Contemporary Calligraphy [J]. Contention of Artistic Thoughts, 2010(04).

[6] Ma Wenlong. Analysis of the Infiltration of Ideological Connotation in Calligraphy Education [J]. Information on Traditional Culture Education, 2013(9). 